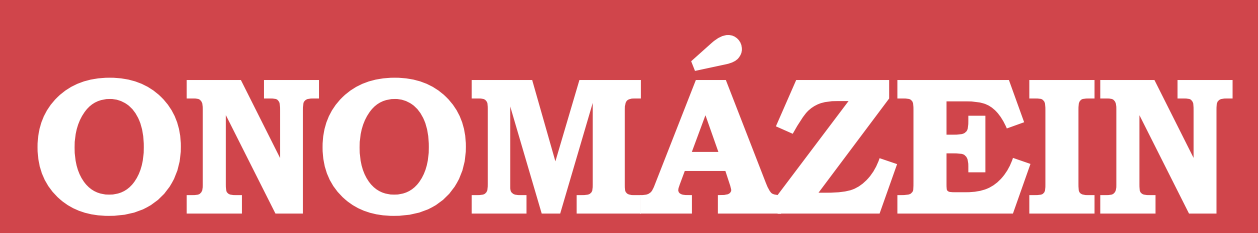

Revista semestral de lingüística, filología y traducción
PONTIFICIA UNIVERSIDAD CATÓLICA DE CHILE CATOLICA DE CHILE
FACULTAD DE LETRAS

\title{
An overview of the approaches and methods for analysing a text from a discursive viewpoint
}

\section{Concepción Hernández-Guerra}

Universidad de Las Palmas de Gran Canaria

España 


\section{Abstract}

Discourse analysis is a modern discipline that has inherited lots of attributes from text analysis. So broad is the range of texts and so different the perspectives under which these texts can be analyzed that we can easily understand the different fields that discourse analysis as a whole can cover. The aim of this paper is twofold: firstly, to clarify the different terms included in the discourse in order to separate the features of this discipline from others, and, secondly, to offer a general vision of all the methods that can be carried out under this umbrella to take the most of the data to be analyzed.

Keywords: discourse; analysis; methods; research. 


\section{Introduction}

It is well-acquainted that discourse analysis can be studied from different theoretical and methodological approaches. Thus, the academic study can be performed from a linguistic, anthropological, philosophical, sociological, poetical, psychological, historical or even communicative perspective (Van Dijk, 1985: 10). These are only some of the possibilities and it is not difficult to guess that, according to the perspective used, results can be different yet equally conclusive.

The reasons to choose one or other frame may reside on the characteristics of the text to be analyzed according to the most revealing information in it to be reported. Discourse and discourse analysis are common concepts employed in large diverse contexts by researchers. Consequently, this is the first problem that scholars face when dealing with this matter. Broadly speaking, discourse as a topic to be analyzed may have different definitions, but according to Schiffrin et al. (2003: 1) all the definitions fall into three main categories: discourse is (1) anything beyond the sentence; (2) language in use, and (3) a broader range of social practice that includes non-linguistic and non-specific instances of language. These three basic categories may be explained by saying that the study of discourse must be done within a context. In this way, any text can be the corpus under analysis, and not only written texts but even spoken data are included. Added to this, the researcher will try to reveal the hidden motivations behind a text. That is, it goes beyond the text. The analysis may even be focused on offering a critical thought to social situations.

This stated, Wetherell (2001) presents four possible approaches to the study of the text as a discourse: firstly, the study of the language as a system. The aim of this approach would be the finding of the patterns in the discourse. Secondly, the language in use as an activity, so the purpose would be the analysis of the interaction between the different elements. Thirdly, the study of the language patterns associated with a given topic or activity. In this case, we are dealing with the English for Specific Purposes where texts are studied within a genre. And fourthly, the pattern study within broader contexts, such as society or culture. Under this umbrella, interest goes beyond the language and studies other possibilities like racism or sexism. The most remarkable example is Critical Discourse Analysis.

Based on this, the main schools created for the academic study of these different fields are:

1. Pragmatics. Analytical approach which involves contextual considerations.

2. Interactional Sociolinguistics. The object of study is the interactive construction and organization of discourse describing it as social interaction. Verbal and nonverbal inputs are considered.

3. Conversational Analysis. Dialogues as they are expressed reveal the conventions in a specific social group. Another example is drama texts as sample for the analysis of the author's style.

4. The Ethnography of Communication. Analysis of language in use in its cultural setting.

5. Sociolinguistic Variation Analysis. The study of the way language varies in communities of speakers. This concentrates in particular on the interaction of social factors (such as a speaker's gender, ethnicity, age, degree of integration into their community, etc.) and linguistic structures (such as sounds, syntactic forms, intonation features, words, etc.).

6. Functional Sentence Perspective bases the research on the sentence structure but with a communicative purpose.

7. Post-Structuralist Theory and Social Theory. They support the idea that theory and reality cannot be separated. Herein the need to study the texts in context even though the reality as we perceive it is relative.

8. Critical Discourse Analysis. They analyze the implicit content in a text in order to define 
the ideological bias. They consider that ideologies are generally implicit assumptions.

9. Mediated Discourse Analysis takes discourse and human action in social change in real time as the basis of the study.

The definition of pragmatics can lead us to conclude that there is not much difference between pragmatics and discourse analysis. Actually, doing discourse analysis primarily consists of doing pragmatics (Brown \& Yule, 1998: 26). The difference could be established in that discourse analysis is a natural consequence of pragmatics. While pragmatics deals with context, discourse analysis, on the other hand, goes into depths in terms of reference, presupposition, implicature and inference. In a way, this prefers to focus on the relationship between speaker and hearer and on the intertextuality rather than the relationship that exists between one sentence or proposition and another.

"Interetextuality" is a concept related to Discourse Analysis coined by Kristeva. It is based on the idea that texts are not independent elements but that all of them have influences from and on others. She distinguishes between "horizontal" and "vertical" intertextuality to distinguish the texts that build on other texts related sequentially (influences) and on other texts that share the same category (e-mails).

Finally and as stated above, context is common in Pragmatics and Discourse Analysis. Discourse will never take texts in isolation but within a context, a background, circumstances that will be taken into consideration giving them the same importance as text itself, but, according to the purpose for the context analysis, different schools have been created.

In summary, grammar, intertextuality and context are necessary in Discourse Analysis. They represent the three necessary elements that comprise the field of study. Grammatical analysis offers the description of the skeleton, the machinery of the text; intertextuality and context define the external elements in which this text was written. The three lead to an exhaustive analysis of the text through which we do not only distinguish the personal style, but even the intention and influences of the author

This stated, the aim of this paper is to offer an overlook on the different methods of analysis carried on by researchers. To do this we shall divide the paper into the remainder chapters: first, we shall explore briefly the origin of discourse analysis as discipline; secondly, we shall discuss the newest tendencies under this discipline; and lastly, we shall explain the different and most important methods used. We shall conclude with some observations

\section{State of the art}

The origins of discourse analysis can be traced back two thousand years ago with the Classical Rhetoric. Actually, Gray, in the introduction of his book The Grammatical Foundations of Rhetoric: Discourse Analysis (1977), affirms that

rhetoric has been the study of extended discourse, and not so much the breaking down to extended discourse as the building up. But like grammar, rhetoric has tended to take for granted the sentence, distinguish it has looked for its data in more extended, complex discourse rather than within sentences.

If we go a bit closer to our era we see that in the sixties Chomsky talked about competence and performance for the first time. Even though he is now questioned, he opens the door to the social component in a text. A bit later, in the seventies and eighties we distinguish between the theoretical and methodological approach in the study of the language, the former being the language use in social contexts, while the second, the organization of language above the sentence. In summary, text is seen as a semantic unit and discourse as a social practice. This was the first step to see the mutual relationship between discourse analysis and other disciplines: anthropology, philosophy, sociology and religion, among others, and even to see the text not as a closed element but rather as a production that provokes a reaction in the receptor. 
This stated, Crystal (1997) defined text linguistics as "the formal account of the linguistic principles governing the structure of texts" and De Beaugrande and Dressler (1986) defined text as "a communicative event" that must satisfy the following seven criteria: 1 . Cohesion, 2. Coherence, 3. Intentionality, 4. Acceptability, 5. Informativity, 6. Situationality, and 7. Intertextuality. The first three criteria are text-internal, that is, they have to do with text linguistics, and the remaining criteria are text-external, closely related with context or, in other words, discourse analysis. Saying it differently, text linguistics is considered a more formal and experimental approach in the study of texts, and discourse analysis covers the functional approach and, consequently, the social.

As we see, differences between text and discourse are essential to understand the origin of this discipline. Simple as it looks, definitions of the concept are varied. Thus, German writers use "text" to refer to speech as well (Coulthard, 1992: 3), while Hoey (1983) and Widdowson use "discourse" to refer to writing. Widdowson (2004) offers a clear-cut distinction between these concepts. According to him, text is the actual use of language, while discourse affects both what a text producer meant by a text and what a text means to the receiver, so the interdependence in discourse is vital and not only the intention but the effect produced can be analyzed. Johnstone (2002: 228) offers another definition to discourse stating that discourse means "actual instances of communication in the medium of language", so discourse analysis is not centered on language as an abstract system. Actually, she says that "discourse is fundamentally the result of flexible strategies, not fixed rules: no interaction is exactly like any other, there is always another way of doing things, idiosyncrasy and novelty are always possible and usually interpretable. But people also need and use fixity."

This idea was also expressed by Brown \& Yule (1998) when explained that even though all the speakers follow certain conventions, we have some personal impromptu on the texts and that ideas can be expressed in different ways, but, they add, this is a reflection of the style yet not necessarily of the intention.

All the expressed above tries to reflect the wide variations these theoretical procedures bring about. The following step would be to clarify which are those broad areas where discourse analysis can be studied in a text. Fairclough (1995: 75) summarizes this subject matter plainly when he states that

text analysis can be organized under four main headings: vocabulary, grammar, cohesion and text structure. [...] In addition, I distinguish a further three main headings which will be used in analysis of discursive practices rather than text analysis, though they certainly involve formal features of texts: the "force" of utterances [...], the "coherence" of texts, and the "intertextuality" of texts.

Quite plainly, Fairclough traces the evolution that the discipline has suffered from the analysis of a text to the analysis of a discourse. As he says, the first four headings are important but constrict the account in a discourse. The most revealing is, as we shall see in the remainder pages, that this has led to new tendencies in the analysis of a discourse.

\section{Current tendencies}

One of the greatest advantages of Discourse Analysis is the nearly endless research possibilities from a theoretical viewpoint. Actually, as John Hyde (2002: 26) stated,

it is counterproductive and ultimately impossible to pose strict compartmentalized borderlines between disciplines such as microlinguistics, macrolinguistics, discourse analysis, text linguistics, pragmalinguistics, corpus linguistics, psycholinguistics, sociolinguistics, and many other areas.

Two propositions can be extracted from this: firstly, more terms are coined according to 
the specifications in the field, while, secondly, there is an impossibility to draw a strict limitation within the different sub-disciplines related to this domain. As an illustration, consider the dialogues in drama, in which questions and answers are worth being analyzed (Coulthard, 1992: 183) but we can also read how to explain irony as a discourse strategy (Peñalba, 2002: 101-107) basing the research on Bakhtin's narrative discourse. Taking all this into consideration, the facts that there can be so many branches as researchers' ideas and that the interrelation between different genres, theories and methodologies is even possible are axiomatic conclusions. In line with this, Crombie (1985: vii) summarizes this idea stating that "the study of discourse must involve the study of every aspect of language", and that is why new tendencies and concepts are invariably being developed. Just to name a couple of them, we face New Criticism. This bases the studies on the idea that "the meaning of a text is in the text" (Johnstone, 2002: 230). They try to avoid a rigorous reading of the text in order to avoid the "intentional fallacy" by doing that. Politolinguistics is another recent concept coined by Reisigl (see Wodak \& Krzyzanowski, 2008: 96) defining it as "the combination of rhetoric, political science and linguistics." For this study he distinguishes between three dimensions of the political: polity, policy and politics.

To sum up, I have tried to express the span and flexibility that researchers own when dealing with discourse: this has the advantage of improving the field with all the possible viewpoints through which a text can be studied while even has the disadvantage of the difficulty in expressing clear-cut approaches. Taking all this into consideration, the following chapter will explore the methods commonly used in discourse research.

\section{Methods of text and discourse analysis}

This chapter will be devoted to the explanation and contrast of the different methods expressed in Titscher et al. Methods of text and discourse analysis, where they offer 12 different methods of analysis; in King et al.'s Designing social inquiry and Creswell's Research Design. Qualitative, quantitative and mixed methods approaches. The purpose is to offer an approximation of the considerations in choosing the most suitable one according to the data and the purpose of the research.

But before that any researcher must put four questions to himself (Burgoyne, 1994: 195, and Titscher et al., 2012: 31):

a. What research question am I trying to answer?

b. What analysis will provide a useful response to the question?

c. To conduct this analysis what data do I need and from whom?

d. What are the practical steps to obtain and record these data?

As it is stated in these preliminary questions and due to the wide spectrum of possibilities for analyzing a text explained above, it is essential to define the purpose of the research and the best sample to carry out that research in order to choose the best method to overcome that research.

The first distinction that must be accomplished before carrying out the research is whether the data will be analyzed from a quantitative or a qualitative approach. Broadly speaking, quantitative applies when the research is performed with a large amount of data. Some examples may be surveys and studies of participants, materials, procedures or measures (Creswell, 2003: 16). On the other hand, qualitative procedures meet a limited amount of data while the variation in the scope of study is much wider. Thus, the study can be carried out with individuals, processes or behavior of individuals. Different possibilities have specific methods. Then, when dealing with individuals, Narrative and Phenomenology are the most suitable methods; when dealing with processes, activities or events, Case Studies or 
Grounded Theory are suitable; and when dealing with the behavior of individuals or groups, Ethnography is the most appropriate.

Another important discrimination that must be defined before the study is whether the study is linguistic or non-linguistic. Most data are linguistic, while in some cases we can face a different approach or even a mixed approach. This would be the case of Grounded Theory or SYMLOG, as we shall see. Non-linguistic corpus would cover studies under Critical Discourse Analysis approach, Objective Hermeneutics and the Ethnography of Communication, where the researcher is more interested in the attitude and behavior than in the text itself. Anyhow, in some occasions it is not easy to classify the methods. Subsequently, we shall expose the different characteristics of every publication cited above.

\subsection{Titscher et al. Methods of text and dis- course analysis (2012)}

This is a comprehensive book that explores in different subchapters all the features of the twelve methods they name. The authors offer the theoretical origins, the basic theoretical assumptions, the objectives, the outline, the method itself, the areas of application and some similarities and differences with other methods. They finish every method with some literature of it. This represents a comprehensive exposition of the most important methods with a clear explanation of the information any researcher could demand. The methods are the following:

4.1.1. Grounded Theory (Glasser/Strauss). This is a methodology for generating theories on the basis of data, which can be linguistic and contextual. The approach is qualitative even though the corpus is usually large amounts of text. Mostly, interviews, notes and observation reports.

4.1.2. Ethnography (Hymes). Ethnography is the study of individual cultures, and formal models of linguistics for the interpretation of human behaviour in cultural contexts are studied.
For this, context is of central importance. This method is qualitative.

4.1.3. Narrative Semiotics (Greimas). Communication consists of semiotic processes, that is, the linking of sign and signified through meanings, so bases the study on the two levels of texts: surface structure and deep structure. This is qualitative and linguistic.

4.1.4. SYMLOG (Bales/Cohen). This is the acronym for "A System for the Multiple Level Observation of Groups" and investigates three levels: verbal and non-verbal behavior, the content of ideas imparted during the communication and the pros and contras values.

4.1.5. Conversation Analysis (Sacks/Schegloff/Jefferson). Ethnomethodology has developed specific methods of text analysis whose particular field of application is everyday conversation and stories. Conversation Analysis is concerned with the communicative principles of the (re-)production of social order in linguistic and non-linguistic interaction.

4.1.6. Objective Hermeneutics (Oevermann). The material used is family conversations or public speeches. The data are broken down into individual meaning units with the purpose of analyzing the reason of the speaker in the use of those syntactic categories. In this discipline, there must be established a distinction between internal and external context.

4.1.7. Membership Categorization Device (Sacks). This is related to sociology and attempts to reconstruct the tools used by the participants for description and categorization. This tries to investigate with conversation analysis everyday rationality, colloquial language and everyday events.

4.1.8. Content Analysis. This is a quantitative and linguistic method with several variations according to the level where it does the research: syntactic, semantic, pragmatics or a mixture among them. 
4.1.9. Functional Pragmatics (Ehlich/Rehbein). This considers speakers and hearers both relevant in the speech action and distinguishes between the surface and the structure in the process. The structure is the socially agreed form while the surface is the single special cases analyzed. The purpose of the speaker is basic in this discipline.

4.1.10. Distinctions Theory Text Analysis (Tischer/Meyer). This is also qualitative and understands communication as a three-stage selection process: information, utterance and understanding. The hearer discriminates the irrelevant information in the process of understanding so the starting point is linguistics.

4.1.11. CDA (Fairclough). CDA stands for Critical Discourse Analysis. This is based on discourse not text. This is non-linguistic and includes intertextuality and sociocultural knowledge.

4.1.12. Discourse Historical Method (Wodak). A key idea in this approach derived from Critical Discourse Analysis is "text planning". The speech situation, the status of participants, time and place, and other sociological variables are determinants in text production. The corpus is interviews, rounds of discussion and the like.

\subsection{King et al.'s Designing Social Inqui- ry. Scientific Inference in Qualitative Re- search (1994)}

We have seen that most methods base their corpus on qualitative research. A deep analysis is better carried out on a delimited data and for the purpose of analyzing specific features is not necessary to have a boundless sample. This is the reason why King et al. focused their publication on the most frequent approach in discourse analysis, that is, the qualitative research. Similarly to the questions posed above, they consider that there are four elements in research design: research question, theory, data and use of data, but researchers should gather that a complete theory is necessary before collecting data while their theory must not remain fixed throug- hout (1994: 46). On the contrary, the theory will be adapted to the features of the data. Consequently, they distinguish between restricted and unrestricted models: the advantage of the restricted is that are clearer although less realistic; on the other hand, the unrestricted models are contextual and more realistic while harder to estimate with precision.

They also offer a formula to calculate the sample mean or average:

$$
\bar{y}=\frac{1}{n}(y 1,+y 2+\cdots y n)=\frac{1}{n} \sum_{i=1}^{n} y i
$$

where $\bar{y}$ represents the average or final result. This is calculated with this simple mathematical operation: $n$ is the total number of elements to which we are going to calculate the average; $y$ followed with a number is the value of the elements themselves. So we simply divide the total sum of the elements to the total number. This operation can be simplified using the Greek symbol sigma where $i$ is a sub-index that differentiates the numbers. Let's see this with an example. We try to calculate the average of three different facts, i.e., the number of times that the first person singular appears in three different texts. We have the numbers 20, 13 and 4. The final formula for this would be

$$
\bar{y}=\frac{1}{3} \sum_{i=1}^{3} 37=12,23
$$

where the final result or $\bar{y}$ is the result of the division of the total sum of all the figures (37) to the total number of figures (3).

\subsection{Creswell's Research Design. Qualita- tive, Quantitative and Mixed Methods Ap- proaches (2003)}

This is a good and useful manual that offers a broad way of how to overcome some research. The authors provide figures that clarify the content and some exercises at the end of every 
chapter. This book is recommended for researchers that want to familiarize themselves with the different methods or for novel researchers in discourse analysis.

Creswell describes step by step all the elements that must be taken into consideration when developing a research model. Thus, he discusses how to define the framework for the design, how to explain the review of the literature and so on. The second part is dedicated to the research design itself including the different methods. He divides them into quantitative, qualitative and mixed. Data collection associated with both forms is also included here (2003: 208). Different examples, figures, suitable data for every method are embodied despite it is not divided up into different specific methods, as seen above. Some writing exercises are also included at the end of every chapter.

If we consider the information gathered in these three manuals, we could design a figure where the different methods with the basic characteristics appear (figure 1 ).

We can see how discourse analysis is more likely to study experimental data from a quantitative approach although it is the qualitative approach the most suitable for this investigation as the conclusions could be better defined. This figure is divided up into linguistic, non-linguistic and mixed approaches, depending on the data to be analyzed. The different methods are classified according to the characteristics, while, as conveyed above, the theory should not be established before the analysis of the data as every sample may have some original characteristics to be analyzed and a refraining method can restrict the possibilities of study.

\section{Conclusions}

The purpose of this paper has been to explain the most recent research fields and methods of discourse analysis. I have tried to offer an overall vision of the elements that must be put into consideration before deciding which method is the most appropriate in a research.

As stated in the first part of the paper, the absence of coincidence in the definition of terms such as text, discourse and so on, provided that they depend on the perspective or aim of every researcher in the use of it, leads us to understand the difficulty there is to delimit the different methods to be used. Broadly speaking, we could say that there can be so many methods as data to be analyzed and researchers to carry out this task, while in a self-contradictory manner

\section{FIGURE 1}

Methods of Discourse Analysis

\begin{tabular}{|c|c|c|c|c|}
\hline & & Linguistic & $\begin{array}{l}\text { Mixed } \\
\text { (Linguistic/non- } \\
\text { linguistic) }\end{array}$ & Non-linguistic \\
\hline & Non-experimental & & & Surveys \\
\hline Quantitative & Experimental & $\begin{array}{l}\text { Content Analysis } \\
\text { Distinction Theory } \\
\text { Text Analysis }\end{array}$ & & \\
\hline Qualitative & & $\begin{array}{l}\text { Narrative } \\
\text { Phenomenology } \\
\text { Functional } \\
\text { Pragmatics }\end{array}$ & $\begin{array}{l}\text { Case studies } \\
\text { Grounded theory } \\
\text { SYMLOG }\end{array}$ & $\begin{array}{l}\text { CDA } \\
\text { Objective } \\
\text { Hermeneutics } \\
\text { Ethnography of } \\
\text { Communication }\end{array}$ \\
\hline
\end{tabular}


nobody argues the need to propose some rules for the accuracy of our conclusions.

Secondly, to avoid this flexibility in the research field it is essential to delimit as narrowly as possible the purpose, scope, data and method used. When doing this, other questions should be answered: what is interesting in this text?, what is revealing?, what originality does it own? Every text, even belonging to the same genre, has those elements that make it worth being analyzed. Nobody must ignore that readers want to read interesting approaches and original proposals, and the appropriate election of the elements to be analyzed is crucial.

Thirdly, we have seen that a qualitative approach can base the study on individuals, processes and behavior, each one having a specific method for their study. For individuals, narrative and phenomenology are appropriate; for processes, case studies and grounded theory, and for behavior of individuals, ethnography is distinguished. Yet, they could be combined according to the aim of the study. Quantitative approach can also base the study on participants, materials, procedures and measures. With large amounts of data the researcher must configure the method that better adjusts to fulfill the purpose of the research. In other words, the researcher has the flexibility to personalize the method in order to take the most of their research.

\section{Bibliographical references}

Brown, Gilian \& George Yule, 1998: Discourse Analysis, Cambridge: Cambridge University Press.

Burgorne, John, 1994: "Stakeholder analysis" in Catherine Cassell \& Gilian Symon (eds.): Qualitative Methods in Organizational Research, London: Sage, 187-207.

Coulthard, Malcolm, 1992: An Introduction to Discourse Analysis, London: Longman.

Crombie, Winifred, 1985: Discourse and language learning: a relational approach to syllabus de- sign, Oxford: Oxford University Press.

CRYSTAL, David, 1997: English as a Global Language, Oxford: Oxford University Press.

De Beaugrande, Robert \& Wolfgang Dressler, 1986: Introduction to Text Linguistics, London: Longman.

FalRclough, Norman, 1995: Critical Discourse analysis, the critical study of language, London: Longman.

Gray, Bennison, 1977: The Grammatical Foundations of Rhetoric: Discourse Analysis, New York: Mouton.

Hoey, Michael, 1983: On the Surface of Discourse, London \& Boston: Allen \& Unwin.

Hyde, John (ed.), 2002: Aspects of Discourse Analysis, Salamanca: Ediciones Universidad de Salamanca.

Johnstone, Barbara, 2002: Discourse Analysis, Massachusetts: Blackwell.

Peñalba, Manuel, 2002: "Irony as a Discourse Strategy: Methods of Ironising a Character in Authorial Narrative" in P. Alonso (ed.): Aspects of Discourse Analysis, Salamanca: Ediciones Universidad de Salamanca.

Schiffrin, Deborah, Deborah Tannen \& Heidei HamILTON, 2003: The Handbook of Discourse Analysis, Malden: Blackwell Publishers.

Van DIJk, Teun, 1985: Handbook of Discourse Analysis, vol. 1, London: Academic Press.

Wetherell, Margaret, 2001: "Debates in Discourse Research" in Margaret Wetherell, Stephanie TayLOR \& Simeon J. YATES (eds.): Discourse theory and practice. A reader, London: Sage, 380-399.

Widdowson, Henry, 2004: Text, context, Pretext: Critical Issues in Discourse Analysis, Malden, M.A.: Blackwell. 
WodAK, Ruth \& Michal KrZYZANOWSKI, 2008: Qualitative Discourse Analysis in the Social Sciences, Basingstoke: Palgrave Macmillan.

\subsection{Primary sources}

CRESWELL, John, 2003: Research design. Qualitative, Quantitative and Mixed Methods Approaches, Thousand Oaks: Sage.

King, Gary, Robert Keohane \& Sydney Verba, 1994: Designing Social Inquiry. Scientific Inference in qualitative Research, Princeton University Press.

Titscher, Stefan, Michael Meyer, Ruth Wodak \& Eva Vetter, 2012: Methods of Text and Discourse Analysis, London: Sage. 